\title{
Parametric Study of to Design an Earth to Air Heat Exchanger with Experimental Validation
}

\author{
Nesrine Hatraf ${ }^{1,2}$, Foued Chabane ${ }^{1,2, *}$, Abdelhafid Brima ${ }^{1,2}$, Noureddine Moummi ${ }^{1,2}$, \\ and Abdelhafid Moummi ${ }^{1,2}$ \\ 1 Mechanical Department, Faculty of Technology, University of Biskra 07000, Algeria \\ 2 Laboratoire de Génie mécanique-LGM-Université de Biskra -Algérie, Algeria \\ *E-mail: fouedmeca@hotmail.fr (Corresponding author)
}

\begin{abstract}
Geothermal energy uses an air ground exchanger to cool buildings with minimum of energy. The outlet air coming from this exchanger can be directly used for space cooling if its temperature is low enough. In this study we try to evaluate the profile of ground temperature to decide of the depth to bury the exchanger. Through modeling and experimentation, we try to evaluate the performance of a horizontal pipe used for cooling, for this finite differential method which consists on dividing the length of the exchanger on multiple equal segments and by the knowledge of initial and boundary conditions the profile of the air temperature is that carry out. The authors conclude that many parameters influence the performance of earth to air exchanger such as the nature of the ground, the ground depth diameter of the duct and the throughput flow.
\end{abstract}

Keywords: Renewable energy, cooling, air/ground exchanger, modeling, geothermal.

ENGINEERING JOURNAL Volume 18 Issue 2

Received 28 May 2013

Accepted 15 October 2013

Published 18 April 2014

Online at http://www.engj.org/

DOI:10.4186/ej.2014.18.2.41 


\section{Introduction}

In this study we are interested in the valorization of renewable energy in general and using the cooling of geothermic energy in particular. This technique has not been used in Algeria yet. Inspite of that, many theoretical and experimental studies, were undertaken: Furthermore, Mihalakakou, et al. 1995 [1] studied the variation of soil depth velocity and the radius for a buried exchanger. The study conducted by P. Hollmuller, 2002 [2] focuses on the use of the air/ground exchanger for heating and cooling buildings. The author treated the heat exchange with a solid medium, of diffusive nature, taking in account the depreciation of temperature often difficult to characterize. This led to the conclusion that the systemic analysis of the coupling of an exchanging air/ground building and a technical system has proved to be fundamental. The purpose of the research presented by B. Peuportier, et al, 2003 [3], is the modeling and the validation of a dynamic model of simulation for Canadian or Provincial well. In this context, the main aim is the study of the potential inertia of the ground as well as the influence of the building. Ghosal, et al, 2003 [4] developed an analytical model to study the effectiveness of earth air heat exchanger coupled with a greenhouse, a comparative study was established between an exchanger buried under the bare surface and under glazed one. The authors concludes that earth air exchanger is more effective in winter than summer, and the results obtained by the exchanger under bare surface are much satisfactory.

De Paepe et al, 2003 [5] analyzed the influence of the exchanger parameters on the thermo hydraulic performance by calculating the thermal effectiveness with pressure drop of the air inside the tube. The author concluded that longer tubes involved drop of effectiveness and high drop pressure, tube with small diameter gives good effectiveness but increases also the drop pressure. The research task carried out by D. Bartolomeu et al, 2005 [6] is devoted to the testing of the performances of a heat exchanger of air/ ground type. Its tested system is a network of 36 tubes $16 \mathrm{~cm}$ in diameter, $25 \mathrm{~cm}$ length, located at various different depths $2 \mathrm{~m} ; 2.5 \mathrm{~m}$; and $3 \mathrm{~m}$. The study was carried out with the aim of getting appropriate dimensions of this system necessary to optimize its performance. Badescu et al, 2007 [7] developed a simple numerical ground heat exchanger model which calculate the ground temperature at the surface and at different depths, The authors concluded that the efficiency of an exchanger depends on several parameters such as pipe depth, dimension of the pipe and its characteristics. Gao et al, 2007 [8] have tested conduction and convection in an arid ground model. Those lasts have estimated thermal diffusivity and water density by applying this new approach; the obtained results were satisfactory in ground temperature (amplitude and phase).

Hakane et al, 2009 [9] developed a new model which consists of three dimensional temperature distribution of the ground integrating real climatic factors. The results obtained shows that the soil temperature of the simulation are very close to the temperature measured. In fact the model can be used for different sites if we know the meteorological data. Bansal et al, 2010 [10] validated experimentally a numerical transient analysis of earth pipe air heat exchanger; the model has been done using FLUENT. The author concluded that for an exchange with $23 \mathrm{~m}$ length and $0.15 \mathrm{~m}$ diameter the temperature drop about (10 to 12$)^{\circ} \mathrm{c}$. In the present study, we begin by an establishment of a simple model which represents best the distribution of the temperature of the ground; from the surface until an optimal depth below it the ground temperature remains constant. This depth depends on the geographical and the climatic data of Biskra situated in the south east of Algeria and considered as an arid region by its warm summer. The second objective is the modeling of the air temperature in the exchanger. Numerical model using FORTRAN software was used to get the distribution of the temperature in the pipe. The variation of many parameters shows the relevant effect to the efficiency of the exchanger (length, diameter, soil depth). The pipe material has not an effect on the performance of the exchanger; we should just use PVC ducts. The Obtained model is confronted with experimental results. The rapport paper presents the effect the mass flow rate and solar radiation in the location of Biskra city of Algeria on the solar collector with and without fins [11-18]. The rapport paper presents the results of an experimental investigation of the performance for a new flat plate solar air heater (SAH) with several obstacles (Type I, Type II, and Type III) and without obstacles (Type IV), and found the optimal value of efficiency was determined for the solar air heater with Type II absorbent plate in flow channel duct for all operating conditions and the collector supplied with obstacles appears significantly better than that without obstacles [19-20].

\section{Ground Temperature Profile}

Instead of estimating thermal diffusivity and water density by applying a precise approach [9] and for more 
accuracy, an experimental process was done to evaluate the particle size of the considered ground, in order to know its characteristics by the help of certain curve [2].

Table 1. The texture of the soil is sandy loam.

\begin{tabular}{lr}
\hline Components & Rate (\%) \\
\hline Clay & 02.55 \\
Fine silt & 05.11 \\
Large silt & 20.09 \\
Sandy & 57.12 \\
Coarse sand & 15.12 \\
\hline
\end{tabular}

According to the exposed result in Table $1 \& 2$, the texture of the ground is sandy loam and by using Hollumer graphs [2]. We can estimate the thermo physical characteristics of this kind of soil.

Table 2. Physic-chemical property of soil.

\begin{tabular}{lcccc}
\hline $\begin{array}{l}\text { Characteristics of } \\
\text { Sandy loam } \\
\text { ground }\end{array}$ & $\mathbf{P H}$ & $\begin{array}{c}\text { Humidity } \\
\mathbf{( \% )}\end{array}$ & $\begin{array}{c}\text { Electrical } \\
\text { conductivity } \\
(\mu \mathrm{S})\end{array}$ & $\begin{array}{c}\text { Diffusivity } \\
\alpha_{\mathrm{g}}\left(\mathrm{m}^{2} / \mathrm{s}\right)\end{array}$ \\
\cline { 2 - 5 } & 7.86 & 44.7 & 1.67 & $2.10-6$ \\
\hline
\end{tabular}

In this study the ground is considered as a semi-infinite solid mass (Fig. 1). The surface of the ground exchanged heat by conduction influenced by the solar radiation of the site, the general equation of the conduction given by:

$$
\frac{\partial T}{\partial t}=\frac{k}{\rho c}\left(\frac{\partial^{2} T}{\partial x^{2}}+\frac{\partial^{2} T}{\partial y^{2}}+\frac{\partial^{2} T}{\partial z^{2}}\right)+\frac{\dot{Q}}{\rho c}
$$

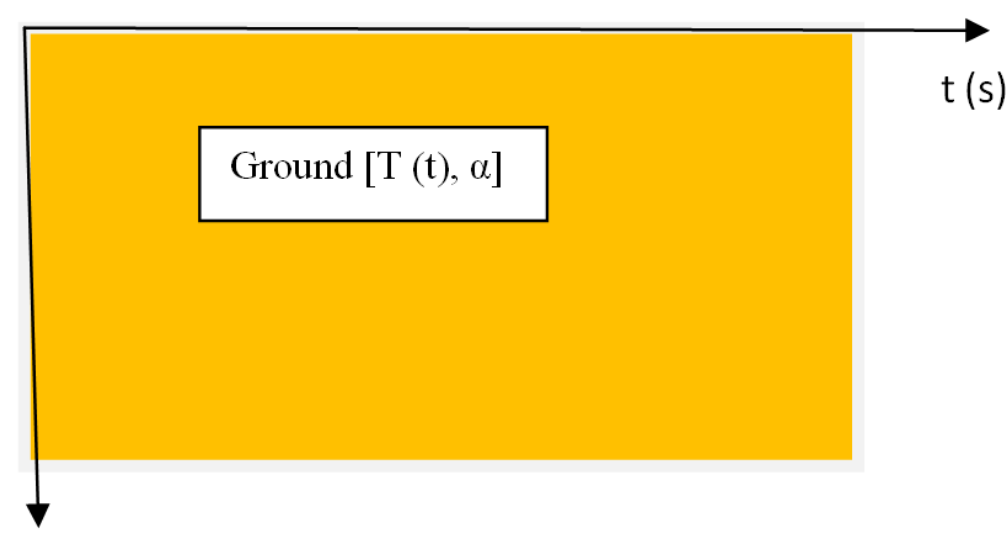

$X(m)$

Fig. 1 Presentation of the model.

Some assumptions are considered to facilitate the resolution:

- The temperature of the ground is less varying along the surface however it changes on depth, only one direction along the depth is taken into account. $\frac{\partial}{\partial y}=\frac{\partial}{\partial z}=0$.

- Without intern heat source Eq. (1) is simplified to be written as:

Let us consider heat conduction in a semi-infinite solid mass $(x>0)$ with an initial temperature of $T_{i}$. At time $t=0$, the surface temperature of the semi-infinite solid mass is suddenly increased to a temperature $T_{0}$. The temperature near the surface of the semi-infinite solid mass will increase because of the surface temperature change, while the temperature far from the surface of the semi-infinite solid mass is not affected and remains at the initial temperature $T_{i}$. The physical model of the problem is illustrated in Fig. 2, 
and the governing equation of the heat conduction problem and the corresponding initial and boundary conditions are:

$$
\frac{\partial T}{\partial t}=\frac{k}{\rho c}\left(\frac{\partial^{2} T}{\partial x^{2}}\right)=\alpha_{g} \frac{\partial^{2} T}{\partial x^{2}}
$$

With the initial and boundary conditions:

$$
T(x, 0)=\frac{\left(1-\alpha_{\text {sol }}\right) G+h_{r} T_{\text {amb }}+\left(h_{r}-h_{e}\right) \frac{b_{\text {lat }}}{a_{\text {lat }}}}{h_{e}}
$$

where $a_{\text {lat }}=103 P a \cdot K^{-1}, b_{\text {lat }}=609 P a, c_{\text {lat }}=0.0168 \mathrm{~K} \cdot \mathrm{Pa}^{-1}$ [4]

$$
\begin{aligned}
& h_{e}=h_{\text {eq }}+h_{\text {surf }} \times c_{\text {lat }} \times a_{\text {lat }} \times f \\
& h_{r}=h_{\text {eq }}+h_{\text {surf }} \times c_{\text {lat }} \times a_{\text {lat }} \times f \times r_{a} \\
& h_{\text {surf }}=0.5+1.2 \sqrt{v}
\end{aligned}
$$

$$
\begin{gathered}
T(0, t)=T_{0} \cos w t+T_{i} \\
T(\infty, t)=T_{i}
\end{gathered}
$$

$\alpha_{\mathrm{g}}$ Diffusivity of the ground $\alpha=\lambda / \varrho \mathrm{c}$

$T_{0}$ Average temperature

The solution obtained by Sacadura [6] is:

$$
T=T_{0} \times e^{\left(-\sqrt{\frac{\omega}{2 a}} x\right)}\left(\cos \left(\omega t-\sqrt{\frac{\omega}{2 a}} x\right)\right)+T_{i}
$$

Figure 2 shows that the ground temperature variation is inversely proportional to the depth, the more one penetrates in the ground, the more the influence of the radiation decreases until a certain value below which the temperature of the ground remains constant, and in this case the depth is around by 3 meters.

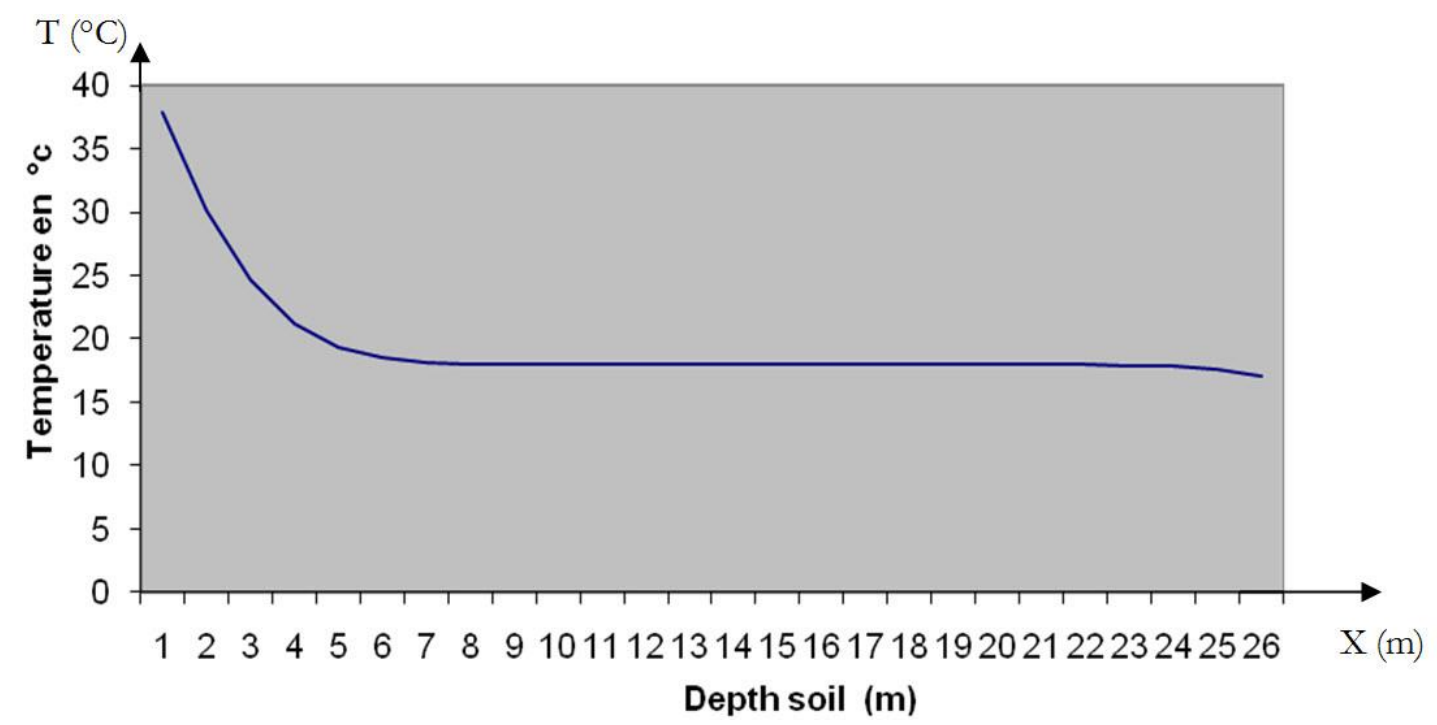

Fig. 2 Distribution of the ground temperature along its depth.

\section{Modeling the Distribution of the Temperature in the Exchanger}

The exchanger which is the object of the study is a PVC conduct undergrounded at $3 \mathrm{~m}$ depth [21], it is composed of two parts (Figs. 3 \& 4). One is vertical 3 meters length, linked with a horizontal one $Y=43 \mathrm{~m}$. The air flow which yields its heat to the ground is characterized by a certain inertia which depends on its texture. In the exit of the vertical conduct, the temperature of the air decreases in comparison to the surface one. 
The length of the vertical section, starting from the surface of the ground is of $3 \mathrm{~m}$. It is the depth beyond which the temperature of the ground remains constant.

In the horizontal conduct, the fluid temperature also decreases but progressively.

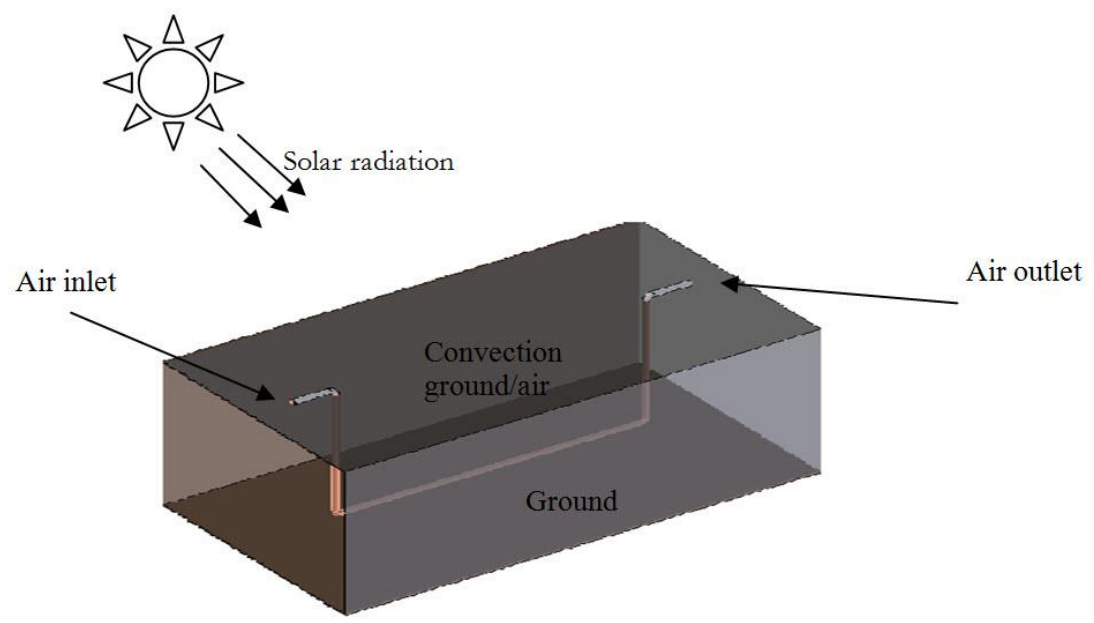

Fig. 3 Presentation of the exchanger buried in the ground.

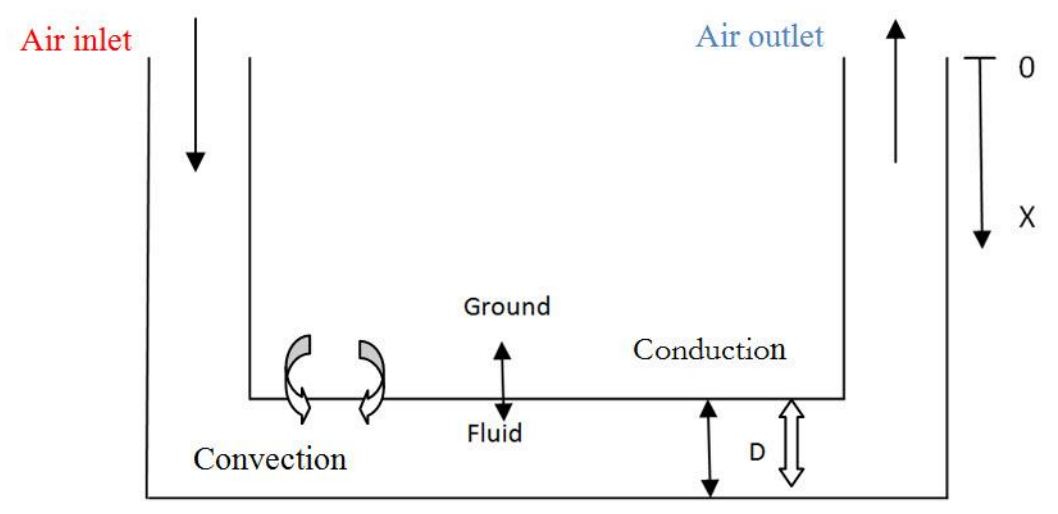

Fig. 4. Geometry of the exchanger buried in the ground.

Table 3. Physical properties suitable soil and PVC tube.

\begin{tabular}{cccccccc}
\hline Soil & $\mathbf{a}_{\text {lat }}(\mathbf{P a} / \mathbf{K})$ & $\mathbf{b}_{\text {lat }}(\mathbf{K} / \mathbf{P a})$ & $\mathbf{c}_{\text {lat }}(\mathbf{P a})$ & $\mathbf{f}$ & $\left.\boldsymbol{\alpha}\left(\mathbf{m}^{2} / \mathbf{s}\right)\right)$ & $\Delta \mathbf{t}($ heure $)$ & $\Delta \mathbf{x} \mathbf{( m )}$ \\
\cline { 2 - 8 } & 103 & 0,0168 & 609 & 0.2 & $2.10-6$ & 1 & 0.2 \\
\hline \multirow{2}{*}{ PVC } & $\mathrm{k}(\mathrm{w} / \mathrm{mK})$ & $\mathrm{C}(\mathrm{j} / \mathrm{KgK})$ & $\varrho\left(\mathrm{Kg} / \mathrm{m}^{3}\right)$ & $\mathrm{d}(\mathrm{m})$ & Length $(\mathrm{m})$ & $\Delta \mathrm{r}(\mathrm{m})$ & $\Delta \mathrm{x}(\mathrm{m})$ \\
\cline { 2 - 8 } & 0.16 & 900 & 1380 & 0.1 & 48 & 0.2 & 0.2 \\
\hline
\end{tabular}

Applying the energy equation to the flow:

$$
\rho \frac{D E}{D t}=\operatorname{div}\left(\lambda_{f} \overrightarrow{\operatorname{grad} T}\right)-P \operatorname{div} \vec{q}+\varphi+\mu\left(\frac{d u}{d y}\right)^{2}
$$

Hypotheses:

- $\quad$ The fluid has constant physical properties.

- The fluid is incompressible, $\operatorname{div} \vec{q}=0$.

- Its movement is unidirectional, along the longitude axis parallel with the axis of the conduct.

- The flow is permanent: $\partial T / \partial t=0$.

- The viscous dissipation $\mu\left(\frac{d u}{d y}\right)^{2}$ and the longitudinal conduction $\lambda_{f}\left(\frac{\partial^{2} T}{\partial x^{2}}\right)^{2}$ are negligible. 
Under these conditions, Eq. (7) becomes:

$\mu$ : Dynamic viscosity

$$
\begin{gathered}
\rho c_{v} u \frac{d T}{d x}=\frac{\lambda_{f}}{r} \times \frac{\partial}{\partial r}\left(r \frac{\partial T}{\partial r}\right) \\
u(r)=\frac{-1}{4 \mu} \times \frac{d P}{d x}\left(R^{2}-r^{2}\right)
\end{gathered}
$$

P: Air pressure

$$
q_{v}=\frac{\pi}{8 \mu} \times\left(R^{4}\left(-\frac{d P}{d x}\right)\right)=u_{m} \pi R^{2}
$$

One replace $\frac{d P}{d x}$ by its value:

$$
u(r)=\frac{u_{d}}{2} \times\left(1-\frac{r^{2}}{R^{2}}\right)
$$

The finite differences method permits (explicit diagram) to solve the heat equation, Fig. 5, it is applied on the ground (vertical section 0 to $3 \mathrm{~m}$ ), in order to obtain the distribution of the temperature along the exchanger. These values of temperatures are regarded as initial conditions for the calculation of the temperatures in the horizontal section of the exchanger.

$$
\begin{aligned}
& \frac{\partial T}{\partial x}=\frac{\alpha_{f}}{u} \times\left(\frac{1}{r} \frac{\partial T}{\partial r}+\frac{\partial^{2} T}{\partial r^{2}}\right) \\
& \frac{\partial T}{\partial x}=\frac{T_{i+1, j}-T_{i, j}}{\Delta x}, \frac{\partial T}{\partial r}=\frac{T_{i, j+1}-T_{i, j}}{\Delta r}, \frac{\partial^{2} T}{\partial r^{2}}=\frac{T_{i, j+1}+T_{i, j-1}-2 T_{i, j}}{\Delta r^{2}} \\
& T(i+1, j)=\left(1-a(j)-\frac{b(j)}{j \Delta r}\right) \times T(i, j)+\left(\frac{a(j)}{2}+\frac{b(j)}{j \Delta t}\right) \times T(i, j+1)-\frac{a(j)}{2} \times T(i, j-1) \\
& \text { with } a(j)=u \times \Delta r \times \alpha \times \frac{\Delta x}{4}\left(1-\frac{(j \Delta r)^{2}}{R^{2}}\right), b(j)=\frac{a(j)}{2 \Delta r}
\end{aligned}
$$

The initial conditions and extreme ones are:

$$
\begin{array}{r}
T(0, j)=T_{0} \cos \omega j+T_{i} \\
\left\{\begin{array}{l}
\frac{\partial T}{\partial r}=0 \rightarrow r=0 \\
T=T_{\text {soil }}(x) \rightarrow r=R
\end{array}\right.
\end{array}
$$

Isothermal condition:

$$
\frac{T_{i+1, j}-T_{i, j}}{\Delta x}=0 \rightarrow x=0
$$

The values of the temperatures in extreme cases of the vertical section are exploited as initial condition to find the distribution of air temperature in the horizontal section, which starts at the end of the vertical one, see Fig. 5. 


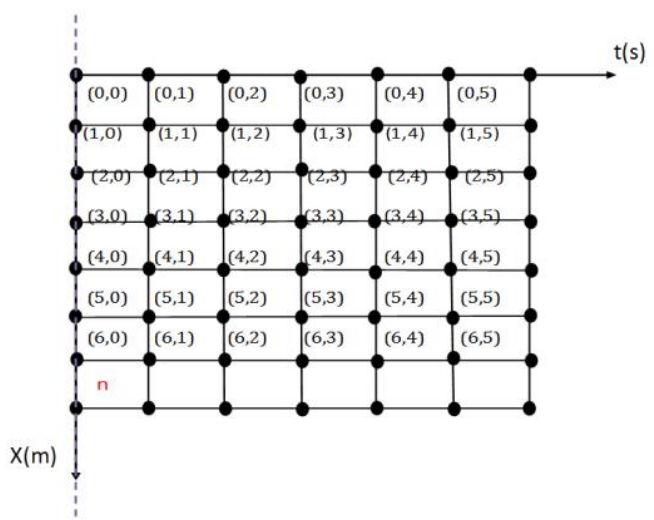

Fig. 5. The grid of the ground.

$$
T(3, j)=T_{\text {sol }}(3, j)=35^{\circ} \mathrm{C}, r=0 \rightarrow \frac{\partial T}{\partial r}
$$

With the air-to-ground contact, the quantity of heat exchanged by conduction is the same as the one, exchanged by convection, this one is written as follows:

$$
\lambda \frac{d T}{d r}=h\left(T_{s o l / r=R}-T_{a}\right)
$$

h: the global transfer coefficient. It takes into account both the convection and the conduction of the pipe.

\section{Experimental Device}

The bench of the experimental tests was assembled at the University of Biskra at longitude $5^{\circ} 44^{\prime}$ east, latitude $34^{\circ} 48^{\prime}$ north, characterized by a saharien climate, warm and dry in summer. The day of the test was the 28 of July 2009 .

Figure 6 below shows a network of 04 traces on overall length of approximately $60 \mathrm{~m}$. The inner diameter of the duct is of $110 \mathrm{~mm}$, the distance between the different ducts is $02 \mathrm{~m}$. The unit is placed at a depth of $3 \mathrm{~m}$ under a slope of $2 \%$ [24]. A pit of reception out of concrete is built on the outlet side of the exchanger. A series of thermal probes of $\mathrm{K}$ type were placed along the exchanger from the entry to the exit. The probes are connected to a power station of acquisition.
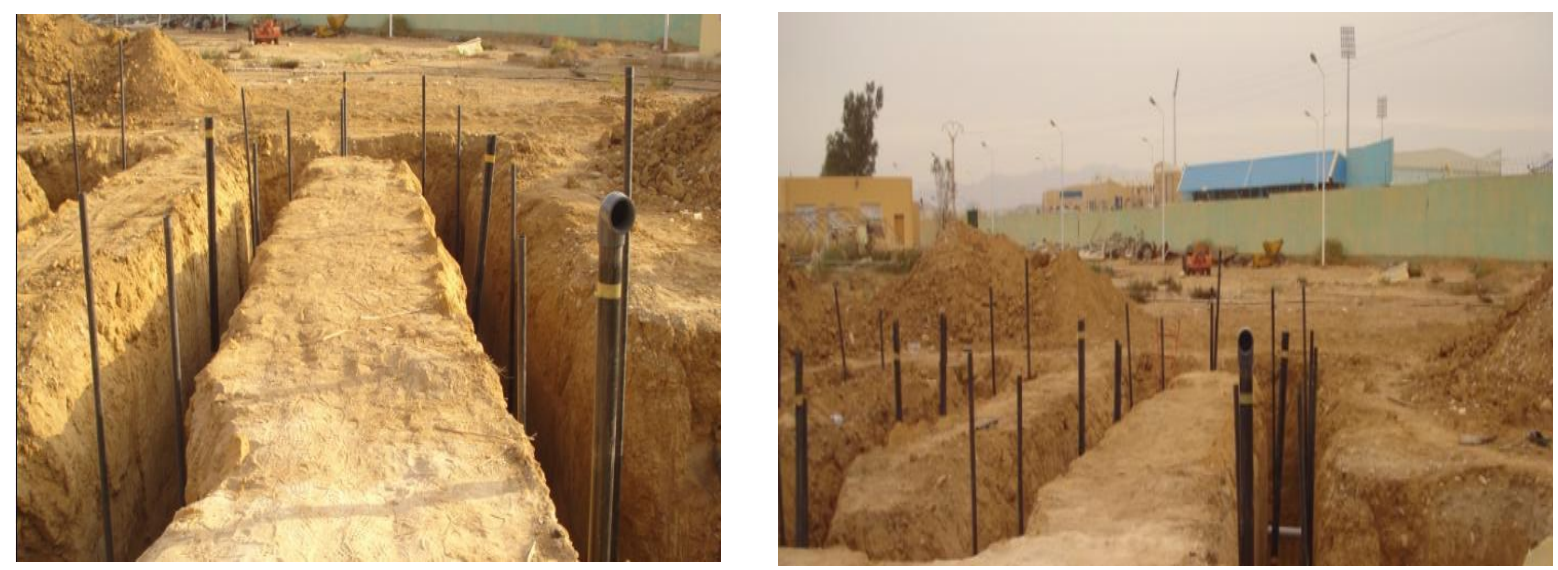

Fig. 6. Presentation of the experimental device.

\section{Results and Discussions}

Figures 7 and 8 show the comparison between numerical and experimental variations of the temperature of the air in the exchanger, for different volume throughputs from the entry to the exit. When the hot air coming from building enters the exchanger, its temperature drops rapidly because of the gradient of the temperature between the ground and the air, after that the variation becomes less considerable. The length 
of the exchanger has an impact just in the first twenty meters. In fact an exaggerated length involves pressure drop and consequently the efficiency of the exchanger fall. Following the considered assumptions, the variation is acceptable. But, in all the cases, the temperature of the air in the pipe drops and opens prospects for a larger use of the geothermal energy.

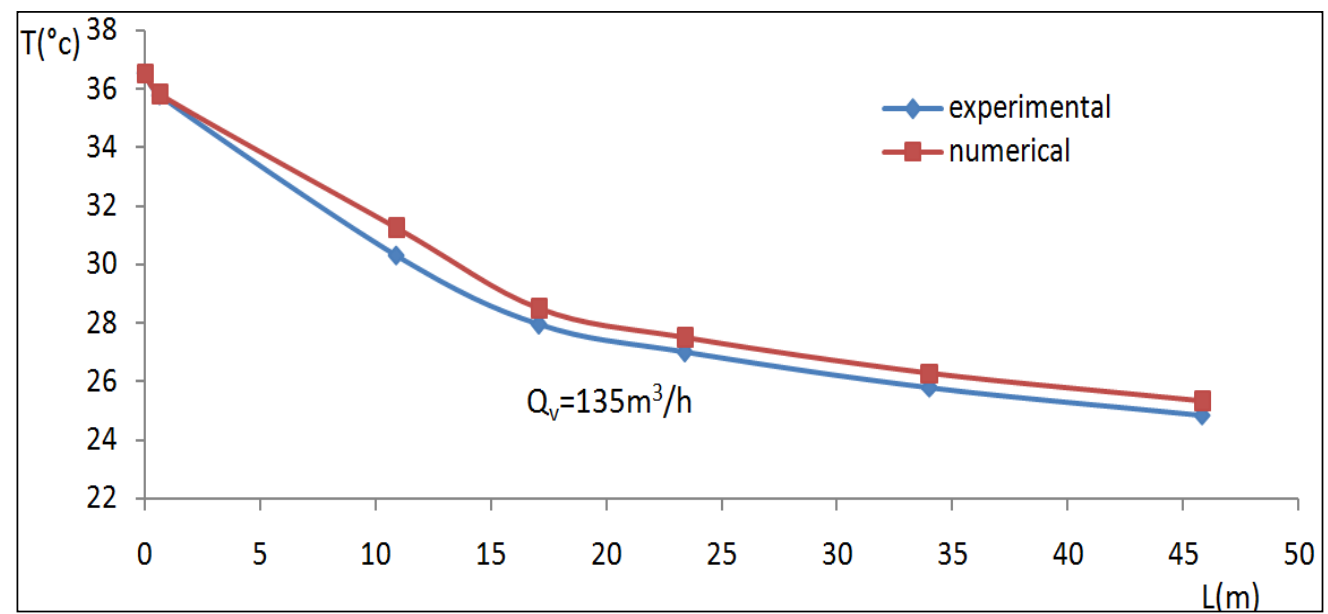

Fig. 7. Comparison between numerical and experimental results of the air temperature distribution along the exchanger to fix the volume throughput

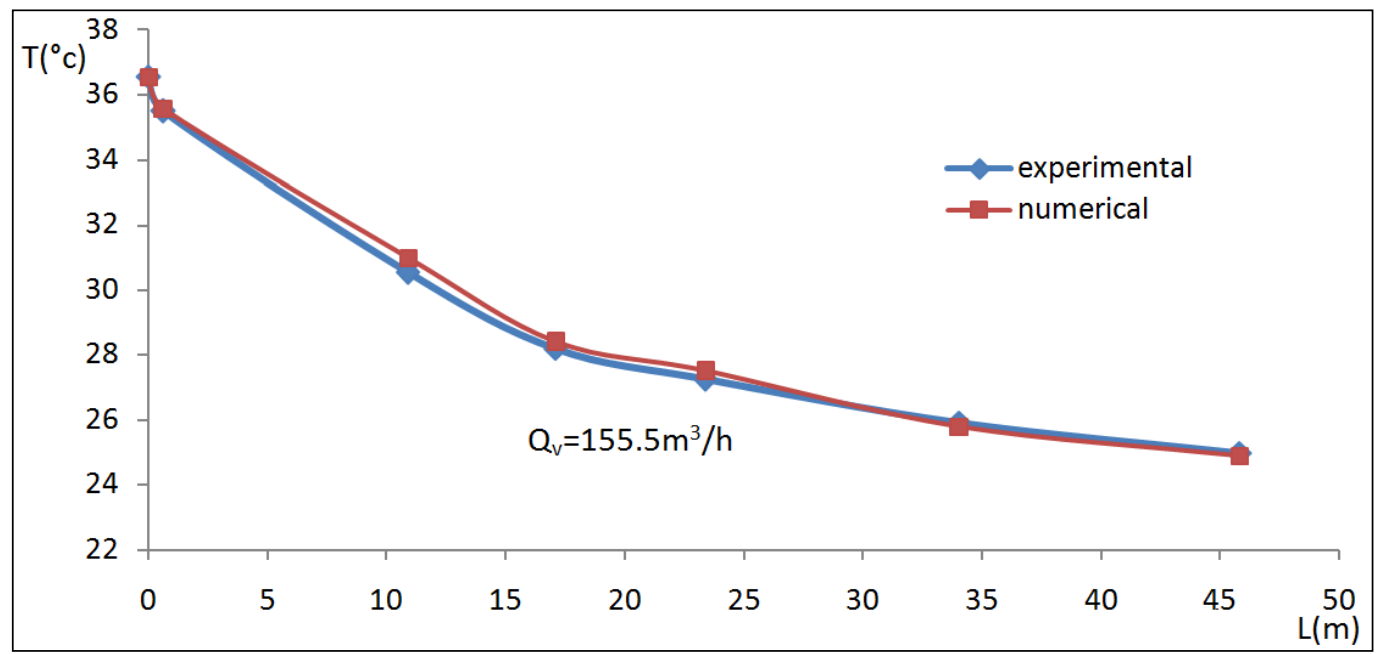

Fig. 8. Comparison between numerical and experimental results of the air temperature distribution along the exchanger.

Figure 9 shows the variation of the air temperature with tube length, represent the inlet and outlet of the buried pipe of the earth-pipe-air heat exchanger system respectively. Fig. 2 represents the comparison of the results of the simulation and experiments for flow rates of 100, 150 and $200 \mathrm{~m}^{3} / \mathrm{s}$ at the outlet of the differences diameters of the pipes respectively. Figure 10 shows the validation of simulated temperatures with experimental results. This is apparent that variation in simulated and experimental results approached between us of experimental results. 


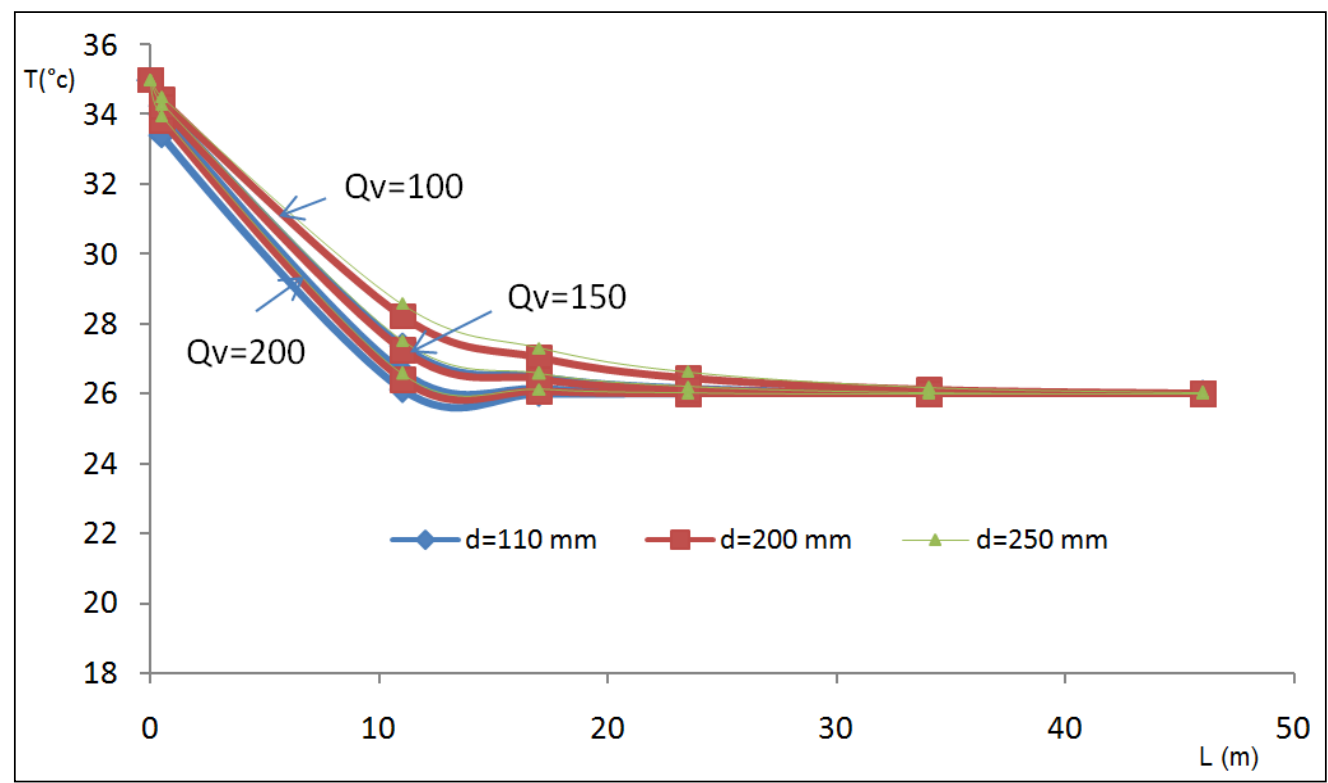

Fig. 9. Numerical distribution of the air temperature along the exchanger according to various volume throughputs and various diameters.

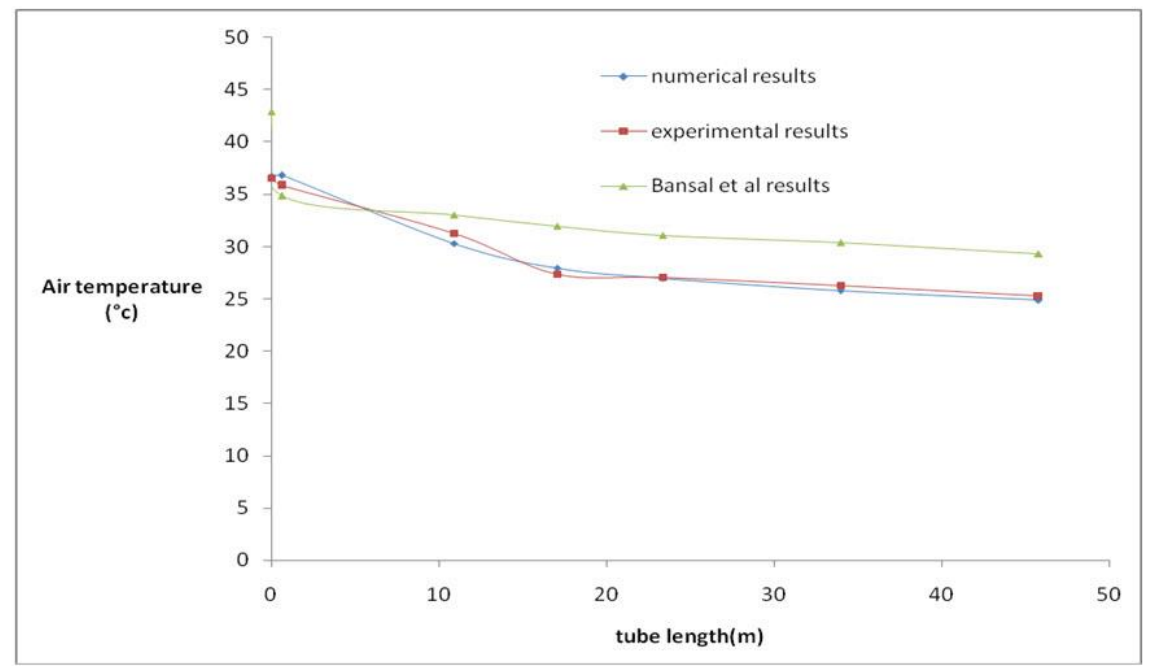

Fig.10. Comparative study between the current results and Bansal, et al. results.

As an illustration, Fig. 10 shows the variation, according to the obtained model, of the temperature of the air along the exchanger for various diameters of the pipe and various flows. To improve the performances of the air ground exchanger, two parameters should be taken into account: the volume throughputs and the exchanger diameter. The curves are the same. Our results can be compared with the ones of Bansal et al [10], presented in Fig. 10, and listed in the references.

The air flow affects considerably the performance of the exchanger, for that we plot in Fig. 8, the variation of Nusselt according to the Reynolds number. This function could be established with more investigations. We can be seen in Fig. 11 the Nusselt Number is increasing with increased the Reynolds Number, correspondently the diameter of the pipe $\mathrm{d}=110 \mathrm{~mm}$; means the coefficient of heat exchange increased with increasing the Reynolds Number. 


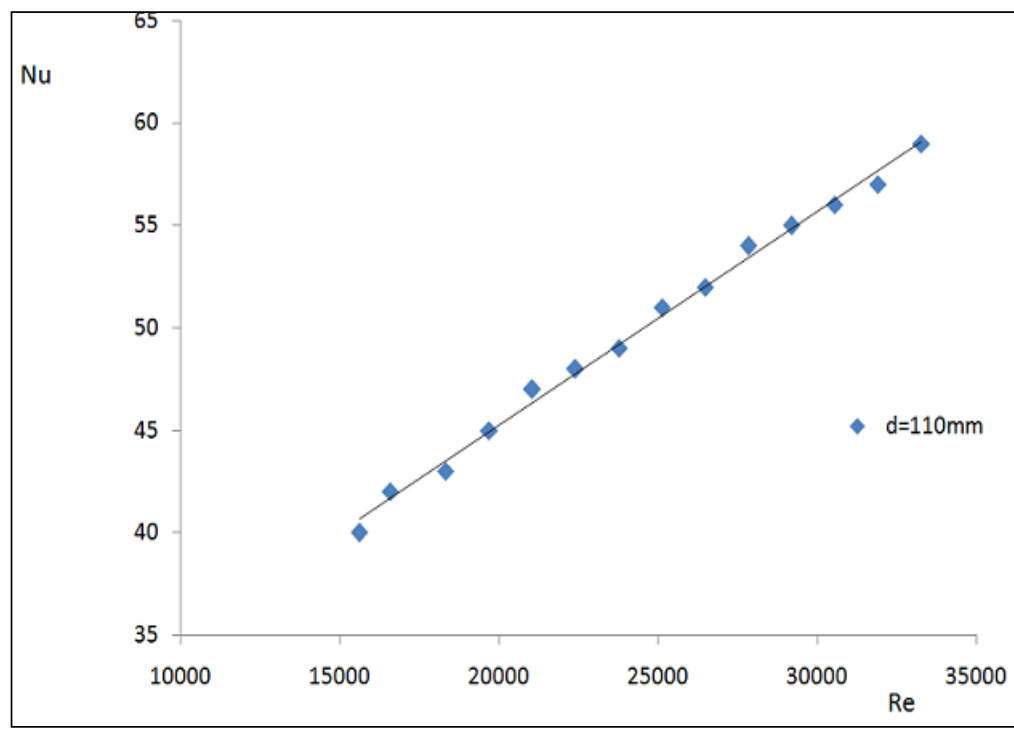

Fig. 11. The variation amongst Nusselt according to the Reynolds number.

\section{Conclusion}

This paper presented the modeling of an air ground exchanger, destined for the cooling of buildings. Using numerical model based on finite difference method, allowed to solve numerically the energy equation to get the optimal depth to bury the exchanger. The optimal depth in this case is about 3 meters.

We have also calculated using a simple model the distribution of the air temperature and varied several parameters such as: the conduct diameter, the volume throughput, the material of the pipe and concluded that the efficiency of an exchanger depends on several parameters such as the pipe depth, the dimensions of the pipe and its characteristics [1,8]:

- The nature of the soil has a high impact on the performance of the exchanger since the soil will transmit the heat to the exchanger.

- It is important to know the depth in which you bury the pipe; as it depends on the diffusivity of the ground.

- The pipe material has not an effect on the performance of the exchanger; we should just use PVC ducts instead of an expensive material which enhances the cost of the earth to air exchanger.

- The temperature of the air inside the pipe decreases more in the entrance and less in the exit, longer tubes involved low effectiveness and a high drop of the pressure [3].

- The Experimental results are close to the numerical ones, so this model can be used in other sites.

- The experimental results show that the technique of cooling buildings by geothermal energy could be exploited in Algeria.

\section{Acknowledgements}

The author wishes to express his gratitude to the department chief of ITAF Algiers institute Mme RAZI for their help in ground analysis, and the responsible of Mechanical Laboratory for his excellent technical assistance.

\section{Nomenclature}

\begin{tabular}{ll}
\hline Symbol & Definition and unit \\
\hline Alat $_{\text {blat }}$ & Empirical constant $[\mathrm{Pa} / \mathrm{K}]$ \\
$\mathrm{C}_{\text {at }}$ & Empirical constant \\
$\mathrm{c}$ & Empirical constant \\
$\mathrm{c}_{\mathrm{V}}$ & Heat- storage capacity of ground $\mathrm{J} / \mathrm{kg}]$ \\
\hline
\end{tabular}




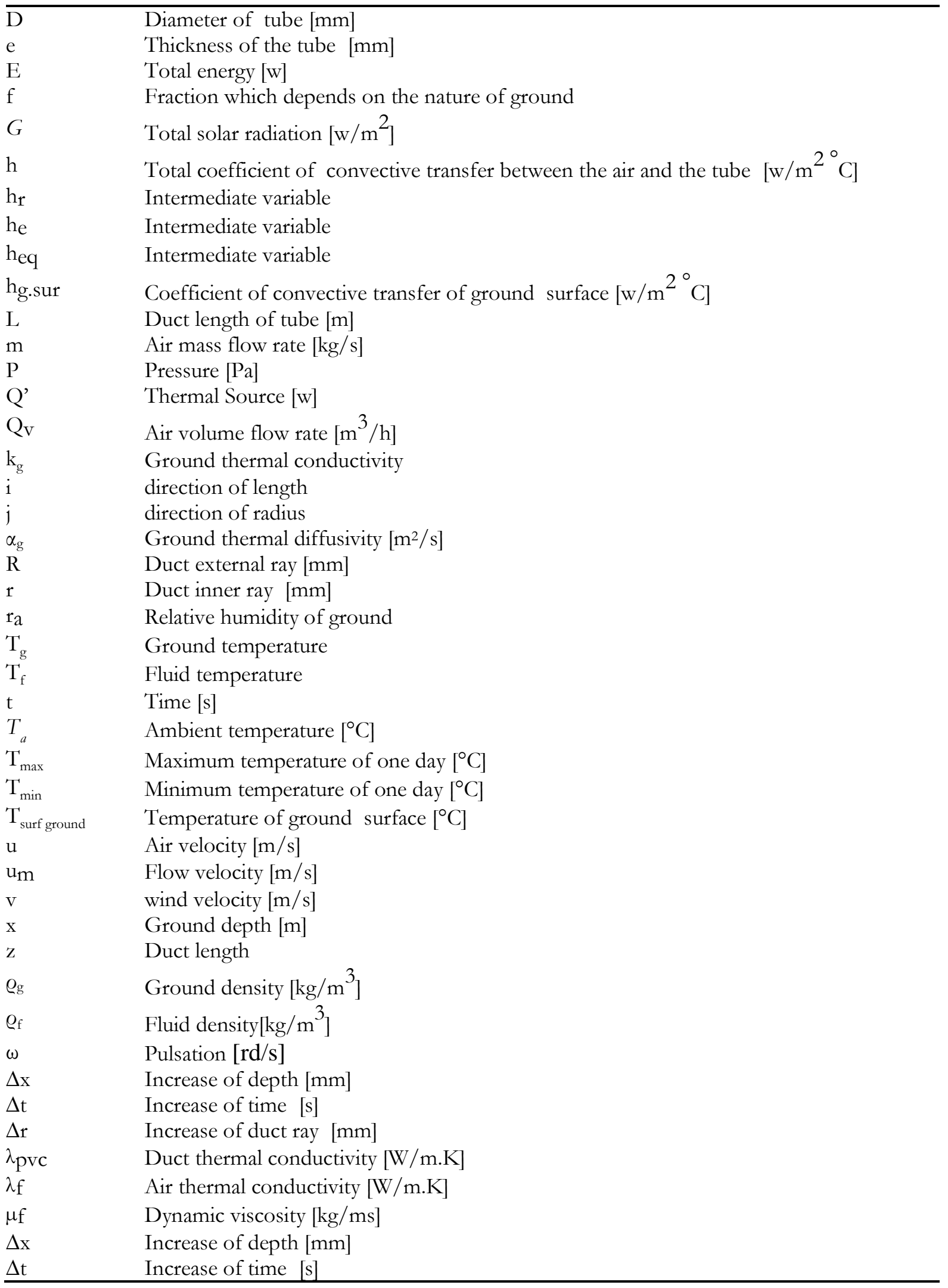




\section{References}

[1] G. Mihalakakou, M. Santamouris, D. Asimakopoulos, and I. Tselepidaki, "Parametric prediction of the buried pipes cooling potential for passive cooling applications," Solar Energy, vol. 55, no. 3, pp. 163-173, 1995.

[2] P. Hollumer, "Utilisation des échangeurs air/sol pour le chauffage et le rafraîchissement des bâtiments. Mesures in situ, modélisation analytique, simulation numérique et analyse systémique," Thèse de Doctorat, Université de Genève, 2002.

[3] M. Paepe and A. Janssens, "Thermo hydraulic design of earth-air heat exchanger," Energy and Building, vol. 35, pp. 389-397, 2003.

[4] S. T. Peuportier, "Modélisation thermique d'un échangeur air-sol pour le rafraîchissement des bâtiments," Centre énergétique et procédés, École nationale supérieure des mines de Paris, France, 2007.

[5] M. K. Ghosal, G. N. Tiwari, and N. S. L. Srivastava, "Thermal modeling of a greenhouse with an integrated earth to air heat exchanger," Energy and Building, vol. 36, pp. 219-227, 2004.

[6] D. Bartolomeu, "Performances d'un échangeur thermique de type air-sol," Techni Porc, vol. 28, no. 3, pp. 27-30, 2005.

[7] V. Badescu, "Simple and accurate model for the ground heat exchanger of a passive house," Renewable Energy, vol. 32, pp. 845-855, 2006.

[8] Z. Gao, L. Bian, Y. Hu, L. Wang, and J. Fan, "Determination of soil temperature in an arid region," Journal of Arid Environments, vol. 71, pp. 157-168, 2007.

[9] D. Harkane, K. Ahmet, and T. Galip, "Heat horizontal parallel pipe ground heat exchanger," Applied Thermal Engineering, vol. 29, pp. 224-233, 2009.

[10] V. Bansal, R. Misra, D. Ghanshyam, and J. Mathur, "Performance analysis of earth-pipe-air heat exchanger for summer cooling," Energy and Building, vol. 42, pp. 645-648, 2010.

[11] F. Chabane, N. Moummi, and S. Benramache. (2013). "Experimental study of heat transfer and thermal performance with longitudinal fins of solar air heater," Journal of Advanced Research [Online]. Available: http://dx.doi.org/10.1016/j.jare.2013.03.001

[12] F. Chabane, N. Moummi, S. Benramache, and A. S. Tolba, "Experimental study of heat transfer and an effect the tilt angle with variation of the mass flow rates on the solar air heater," Int J Sci Eng Invest, vol. 1, no. 9, pp. 61-5, 2012.

[13] F. Chabane, N. Moummi, and S. Benramache, "Experimental performance of solar air heater with internal fins inferior an absorber plate: in the region of Biskra," Int J Energy Technol, vol. 4, no. 33, pp. $1-6,2012$.

[14] F. Chabane, N. Moummi, A. Brima, and S. Benramache. (2013). "Thermal efficiency analysis of a single-flow solar air heater with different mass flow rates in a smooth plate," Frontiers in Heat and Mass Transfer (FHMT) [Online]. Available: http://dx.doi.org/10.5098/hmt.v4.1.3006

[15] F. Chabane, N. Moummi, S. Benramache, D. Bensahal, and O. Belahssen. (2013). "Collector Efficiency by Single Pass of Solar Air Heaters with and without Using Fins," Engineering Journal [Online]. Available: http://dx.doi.org/10.4186/ej.2013.17.3.43

[16] F. Chabane, N. Moummi, and S. Benramache, "Effect of the tilt angle of natural convection in a solar collector with internal longitudinal fins," Int J Sci Eng Invest, vol. 1, no. 7, pp. 13-7, 2012.

[17] F. Chabane, N. Moummi, and S. Benramache, "Experimental analysis on thermal performance of a solar air collector with longitudinal fins in a region of Biskra, Algeria," Journal of Power Technologies, vol. 93, no. 1, pp. 52-58, 2013.

[18] F. Chabane, N. Moummi, S. Benramache, O. Belahssan, and D. Bensahal, "Nusselt number correlation of SAH," Journal of Power Technologies, vol. 93, no. 2, pp. 100-110, 2013.

[19] E. K. Akpinar and F. Koçyiğit, "Experimental investigation of thermal performance of solar air heater having different obstacles on absorber plates," International Communications in Heat and Mass Transfer, vol. 37, pp. 416-421, 2010.

[20] E. K. Akpinar and F. Kocyiğit, "Energy and exergy analysis of a new flat-plate solar air heater having different obstacles on absorber plates," Applied Energy, vol. 87, pp. 3438-3450, 2010.

[21] N. Hatraf, N. Moummi, A. Brima, A. Moummi, and S. Youcef Ali. (2010). Etude théorique et expérimentale d'un échangeur air/sol enterré destiné au rafraichissement des locaux [Online]. Available: http//www.cder.dz 
[22] F. Sacadura, "Initiation aux transferts thermiques," Technique et documentation, Cast. INSA de Lyon. Paris, 1980.

[23] M. M. Salah El-Din, "On the heat Flow into the ground," Renewable Energy, vol. 18, pp. 473-490, 1999.

[24] N. Moummi, A. Moummi, K. Aoues, C. Mahboub, and S. Youcef Ali, "Systematic forecasts of solar collector's performance in various sites of different climates in Algeria," International Journal of Sustainable Energy, vol. 29, no. 3, pp. 142 - 150, 2010.

[25] N. Moummi, H. Benfatah, N. Hatraf, A. Moummi, and S. Youcef Ali. (2010). Le rafraîchissement par la géothermie: étude théorique et expérimentale dans le site de Biskra. Revue des Energies Renouvelables [Online]. vol. 13, no. 3, pp. 399 - 406. Available: http/www.cder.dz 
